\title{
Transition in HCB Editor-in-Chief
}

\author{
Jürgen Roth ${ }^{1}$
}

Accepted: 17 November 2015

(C) Springer-Verlag Berlin Heidelberg 2015

Histochemistry and Cell Biology is pleased to announce the appointment of three new Editors-in-Chief and the further growth of its Editorial Board, starting with this issue. Detlev Drenckhahn has stepped down as an Editor-in-Chief after more than 20 years in that role for HCB. The Editorial Board, journal staff, and particularly me as his Editorin-Chief partner, wish to express our sincerest appreciation for his years of meritorious service, and wish him all the best for the future. The new structure of the board of Editors-inChief is an important move to furthermore improve the service for our international authors. We are fortunate to have the pleasure of announcing that Takehiko Koji will serve as Editor-in-Chief for our authors from "Asia-Pacific", Michael Schrader as Editor-in-Chief for "Greater Europe", and Douglas J. Taatjes as Editor-in-Chief for "The Americas".

Jürgen Roth

jurgen.roth@bluewin.ch

1 University of Zurich, Zurich, Switzerland

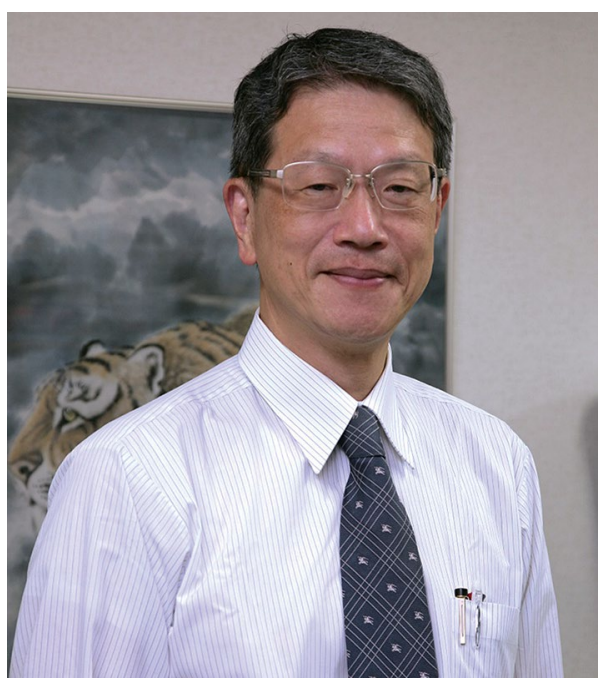

Takehiko Koji received his B.Sc., M.Sc. and Ph.D. in physiological chemistry from The University of Tokyo, Japan. He then joined Professor Paul K. Nakane at the Department of Cell Biology in Tokai University School of Medicine as an Instructor. Afterwards he became Assistant Professor in the Department of Histology and Cell Biology of Nagasaki University School of Medicine and continued to work with Paul Nakane. After a 2-years stay as Visiting Scientist in the Oregon Regional Primate Research Center (USA) with Dr. Robert M. Brenner, he returned to the Department of Histology and Cell Biology of Nagasaki University, where he was initially appointed as Associated Professor and in 1998 promoted to Full Professor. During the past decade, Takehiko served as Vice President of Nagasaki University and as Dean of Nagasaki University Graduate School of Biomedical Sciences. Currently he is serving as a member of the Science Council of Japan, is Chairperson of the Board of Directors of the Japan Society of Histochemistry and Cytochemistry 
and is Vice President of the Japan Society of Microscopy. He became member of the Editorial Board of Histochemistry and Cell Biology in 2002. Takehiko has followed his interest in the molecular mechanisms underlying the regulation of mammalian spermatogenesis, especially in relation to germ cell apoptosis, over many years. To analyze this, he has developed or improved various molecular histochemical techniques including non-radioactive in situ hybridization at both light and electron microscopic levels. Recently, he has made much effort to visualize epigenetic parameters such as DNA methylation and histone modification, which are involved in the regulation of gene expression closely related to germ cell differentiation.

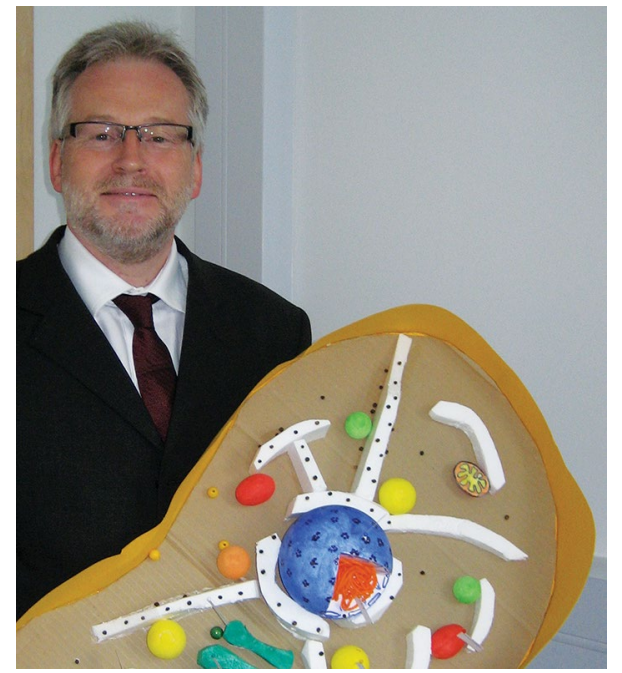

Michael Schrader received his Diploma in Biology from the University of Bielefeld in Germany. He then moved to the University of Heidelberg in Germany to obtain a Ph.D. in Cell Biology with Professor H. Dariush Fahimi. He was awarded a German Research Council research fellowship for postdoctoral research on membrane dynamics and cell polarity at the Johns Hopkins University in Baltimore with Professor Trina Schroer. After leaving the USA, Michael returned to Germany and became a group leader at the University of Marburg, Institute of Cell Pathology (with Professors Horst Kern and Roland Lill), where he habilitated with venia legendi in Cell Biology. Michael then moved to the University of Aveiro (Portugal), where he founded the "organelle dynamics and disease" group within the Centre for Cell Biology and Department of Biology. In 2012, he became an Associate Professor in Cell Biology at the School of Biosciences, University of Exeter (UK), where he is highly active in both research and teaching roles within the University. Michael has been a member of both the German and American Societies for Cell Biology. He became member of the Editorial Board of Histochemistry and Cell Biology in 2006. Michael's laboratory has made extensive use of imaging techniques, notably fluorescence-based approaches and electron microscopy, to elucidate molecular mechanisms underlying the biogenesis and dynamics of subcellular organelles in mammalian cells. His research is at the interface of molecular cell biology and biomedicine and focuses on the molecular machinery and signaling pathways, which mediate and regulate the formation, dynamics, abundance and interplay of organelles, with particular interest in peroxisomes. Michael is a member of the EU Marie Curie Initial Training network PERFUME (Peroxisome Formation, Function and Metabolism). The goal of his work is to understand how organelle dynamics relate to organelle functionality and how this impacts on both the normal healthy state and on disease. His current research focuses on assessing how peroxisome dynamics are regulated and how peroxisomes and mitochondria cooperate to maintain cellular functions.

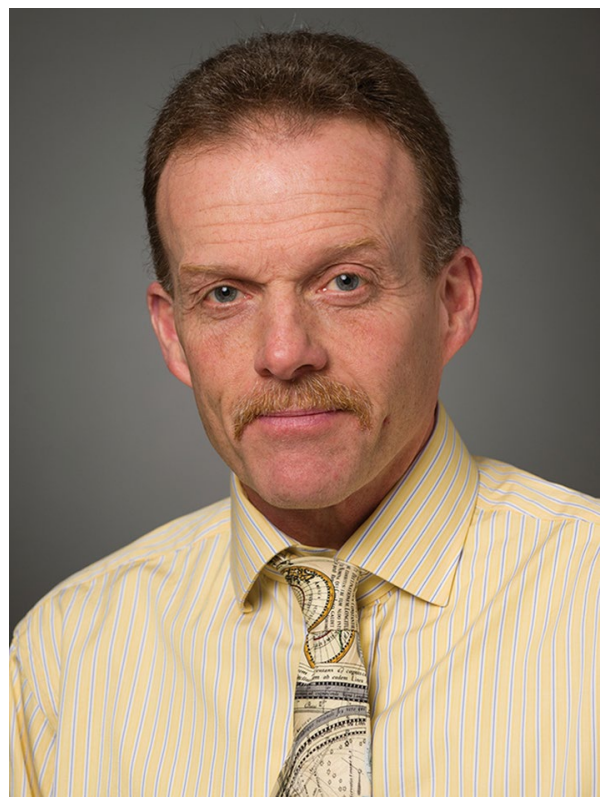

Doug Taatjes received his B.S. in Biological Sciences from the University of Lowell, MA, where he developed skills in electron microscopy and enzyme cytochemistry in the laboratory of Prof. E.R. Rivera. He then moved to Kansas State University and obtained an M.S. in Anatomy and Physiology, working in the laboratory of Prof. Jane Westfall. Thereafter, he moved to Switzerland and obtained a Ph.D. in Cell Biology from the Biocenter at the University of Basel, working in the laboratory of Prof. Jürgen Roth, where he learned the techniques of immunoelectron microscopy and immunofluorescence microscopy. Following completion of his doctoral degree, he moved to the Department of Pathology in the College of Medicine at the University of Vermont where he established his own laboratory and also served as Director of the Electron Microscopy Facility. He has since risen through the academic 
ranks to full professor, and in 1994 helped establish the College-wide Microscopy Imaging Center, where he has served as Director since its inception. He enjoys teaching techniques in imaging, and in 2015 was inducted into The Teaching Academy at the University of Vermont College of Medicine as a "Distinguished Educator". Doug's research interests include using a variety of microscopy-based imaging approaches, often in combination with immunocytochemical techniques, to investigate topics in cardiovascular disease, pulmonary pathology, and cell secretion. He has co-authored over 130 research papers, all featuring aspects of microscopy and imaging, and has co-edited three books on microscopy imaging techniques. Doug has served on the Editorial Board of Histochemistry and Cell Biology since 2002.

Jürgen Roth, Senior Editor-in-Chief Histochemistry and Cell Biology 